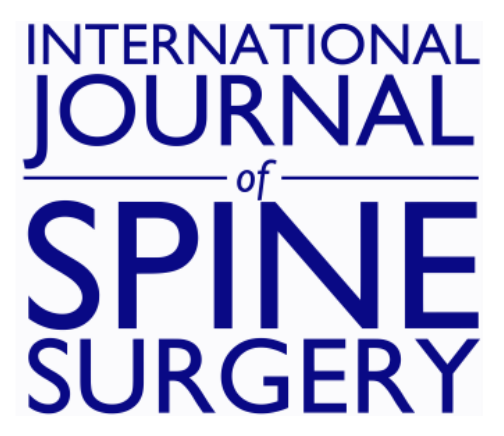

\title{
Metastasectomy and Targeted Therapy for Patients With Spinal Metastases of Renal Cell Carcinoma
}

\author{
DMITRII PTASHNIKOV, NIKITA ZABOROVSKII, STANISLAV KOSTRICKII, DMITRII \\ MIKAYLOV, SERGEI MASEVNIN, OLEG SMEKALENKOV and IRAKLI KUPARADZE
}

Int J Spine Surg 2020, 14 (6) 982-988

doi: https://doi.org/10.14444/7147

http://ijssurgery.com/content/14/6/982

This information is current as of April 26, 2023.

Email Alerts Receive free email-alerts when new articles cite this article. Sign up at: http://ijssurgery.com/alerts 


\title{
Metastasectomy and Targeted Therapy for Patients With Spinal Metastases of Renal Cell Carcinoma
}

\author{
DMITRII PTASHNIKOV, MD, PHD, D OF SC, ${ }^{1,3}$ NIKITA ZABOROVSKII, MD, PHD, ${ }^{1}$ STANISLAV \\ KOSTRICKII, MD, ${ }^{2}$ DMITRII MIKAYLOV, MD, PHD,${ }^{1}$ SERGEI MASEVNIN, MD,${ }^{1}$ OLEG \\ SMEKALENKOV, MD, PHD, ${ }^{1}$ IRAKLI KUPARADZE, MD ${ }^{3}$ \\ ${ }^{I}$ Spine Surgery and Oncology Service, R.R. Vreden Russian Research Institute of Traumatology and Orthopedics, Saint-Petersburg, Russia, ${ }^{2}$ Urology Department, \\ Moscow Oncology Hospital No. 62, Moscow, Russia, ${ }^{3}$ North-Western State Medical University named after I.I. Mechnikov, Saint-Petersburg, Russia
}

\begin{abstract}
Background: Renal cell carcinoma (RCC) is an aggressive malignant disease that frequently metastasizes to the spine. The main purpose of our study is to evaluate the influence of surgery as well as targeted therapy on the survival of patients with RCC metastases of the spine.

Methods: Retrospective cohort study. We identified 100 patients with spinal RCC metastases who were retrospectively reviewed for preoperative conditions, treatment, and survival. Metastasectomy was performed in 39 cases, and 61 patients underwent decompression procedures with stabilization. Only 26 patients had adjuvant targeted therapy ( 7 with metastasectomy, 19 with palliative decompression). Pain, neurological status, survival time (from operation to death or last follow up), and local progression-free survival were evaluated.

Results: Neurological function recovery and reported significant pain relief were observed. There was no significant difference in overall survival for the patients with metastasectomy and palliative decompression $(P=.750)$. Metastasectomy provided better local control of disease compared with decompression $(P=.043)$. There was a statistically significant difference in overall survival for the patients who received targeted therapy $(P=.012)$.

Conclusions: Metastasectomy is effective for local control of tumors. Targeted therapy can potentially prolong overall survival for patients with spinal RCC metastases.

Level of Evidence: 3.

Clinical Relevance: Our findings suggest that spinal metastasectomy is useful for local control of tumor growth but not for live expectancy. Effective systemic therapy is key role in stopping of disease progression.
\end{abstract}

Tumor

Keywords: spine, metastasis, tumor, survival

\section{INTRODUCTION}

With a growing prevalence of oncologic pathology in patients, spinal tumor lesions are emerging as a major health care issue, underlining the necessity of carefully analyzed outcomes related to therapeutic options. Most patients with systemic cancer develop skeletal metastases, and the spine is most commonly involved. ${ }^{1}$ Spinal metastases of renal cell carcinoma (RCC) are highly destructive and cause hypervascular lesions. They often cause intractable pain, neurological deficits, and paraplegia, thus substantially reducing the quality of life and increasing mortality., According to Jung et $\mathrm{al}^{4}{ }^{4}$ the 5-year survival rate of patients with bone metastases in the spine is $9 \%$ compared with $30 \%$ in the appendicular skeleton.

Surgical treatment options for patients with spine tumors have undergone a substantial paradigm shift from goals that were only palliative to curative strategies, including complete en bloc resection of the tumor. ${ }^{5}$ Recent advances in molecular biology have led to the development of novel agents such as targeted drugs for the treatment of RCC metastases. A substantial improvement of patients' outcomes has been achieved after treatments with these targeting agents. ${ }^{6}$

The purpose of this study was to analyze outcome and survival of the patients with spinal metastases of RCC. The hypothesis is that metastasectomy as well as targeted therapy influences survival.

\section{MATERIALS AND METHODS}

The study was approved by the research ethics committee. All patients gave informed consent before being included in the study. All procedures 
Table 1. Patients' data.

\begin{tabular}{lc}
\hline Parameters & Total $(\mathbf{n}=\mathbf{1 0 0})$ \\
\hline Sex, n & 76 \\
Male & 24 \\
Female & $58.4(56.1-60.7)$ \\
Age, mean (95\% CI), y & 75 \\
No. of levels & 22 \\
1 & 3 \\
2 & \\
3 & 50 \\
Neurological status before surgery, n & 50 \\
Frankel A, B, C & $11.1(10.6-11.6)$ \\
Frankel D, E & $11.6(10.8-12.4)$ \\
Revised Tokuhashi score, mean (95\% CI) & \\
SINS, mean (95\% CI) & 66 \\
Metastases, $\mathrm{n}$ & 8 \\
Synchronous & 42 \\
Solitary spinal metastases & 50 \\
Extravertebral bone metastases & 87 \\
Additional visceral metastases & 26 \\
Radical nephrectomy prior spine surgery, n & \\
Targeted therapy after spine surgery, n & \\
\hline
\end{tabular}

Abbreviation: CI, confidence interval; SINS, Spinal Instability Neoplastic Score.

involving human participants were in accordance with the 1964 Helsinki declaration and its later amendments. Our retrospective study included patients undergoing surgery for spinal metastases of RCC operated on within 2005 and 2016. Analyzed data consisted of 100 patients with a median age of 56 years (range $=23-74$; Table 1 ). Inclusion criteria were pain and/or paralysis caused by spinal instability or tumor compression. Exclusion criteria were minimal invasive interventions (vertebroplasty, etc) or contraindications for operative treatment. Medical records for these patients were reviewed. Patient demographics data, neurological status, disease location, intraoperative and postoperative events, and other treatments were collected.

Before surgery, all patients received magnetic resonance imaging (MRI) examinations of the spine to visualize the extent of tumor in the vertebral column and spinal canal. A multidisciplinary team performed a systemic search for visceral and other osseous metastases. This survey included abdominal and renal sonographies; computed tomography (CT) of the chest, abdomen, and pelvis; and nuclear scintigraphy or positron emission tomography-CT. CT or MRI of the brain was provided if clinically indicated.

Indications for surgery included severe back or extremity pain, clinical or radiographic evidence of instability, and neurological dysfunction. There were 2 types of operative treatment. (1) Metastasectomy involved total tumor resection (spondylectomy of affected vertebrae), replacement of vertebral body with implant, and instrumental spinal stabilization. In the thoracic region, we used a posterior approach; in cervical and lumbar regions, anterior and posterior (2-stage surgery). (2) Patients with metastases of RCC in bones and other organs, having severe neurological status and rapid progression, obtained decompression. It included partial tumor excision (tumor curettage or debulking) with resection of the posterior column (pedicles, facet joints, vertebral arc) and instrumental stabilization of the spine. The choice of surgery depended upon the type of lesion (focal or multiple). Also, we performed spinal metastasectomy in cases of oligometastases. We believe that en bloc resection of hypervascular lesions can be less traumatic in the thoracic spine (posterior 1-stage surgery). Moreover, some patients underwent metastasectomy for spinal restoration after severe kyphotic deformity. The final decision was developed by multidisciplinary management through evaluation of life expectancy and possible treatment options.

After spine surgery, all patients received adjuvant therapy. According to the multidisciplinary approach, the type of therapeutic agent was decided by the chemotherapist. Targeted therapy (bevacizumab with interferon, everolimus, pazopanib, sorafenib, sunitinib, temsirolimus, or tivozanib) was given to 34 patients, whereas 75 patients received cytokine therapy (interferon or interleukin-2).

A visual analog scale (VAS) for back pain ranging from 0 to 10 was collected with 0 representing no pain and 10 reflecting the most unbearable pain. Neurological status was estimated by the Frankel scale. Complications were defined as any event when a patient required specific treatment. Survival was evaluated from spinal surgery to death or last follow up.

\section{Statistical Methods}

Statistical analyses were provided by $\mathrm{R}$ version 3.3.2 (R Foundation for Statistical Computing, Vienna, Austria). For categorical variables, crosstabulations were generated, and Pearson's $\chi^{2}$ test with Yates' continuity correction Mann-Whitney test was used for continuous variables. Paired Wilcoxon test was used for comparing preoperative and postoperative parameters. The Kaplan-Meier analysis method estimated postoperative survival and survival curves using the log-rank test. A $P$ value less than .05 was considered to be statistically significant. 

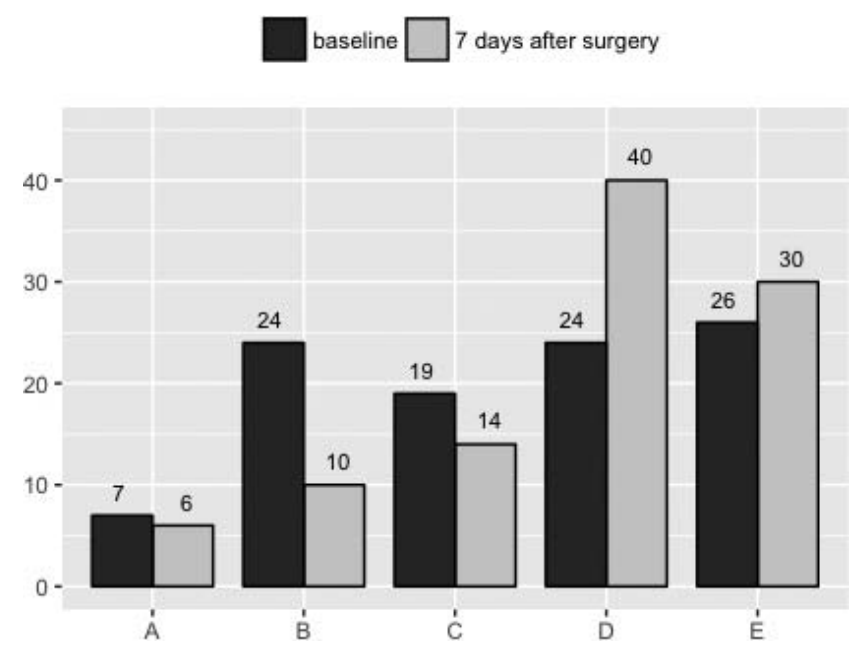

Figure 1. Neurological status of patients by Frankel scale.

\section{RESULTS}

Before spinal surgery, $87 \%$ of the patients had radical nephrectomy. The tumor lesions were mainly located in the thoracic region (48\%), with a lower percentage in lumbar $(37 \%)$ and cervical regions $(15 \%)$. Most of the patients $(66 \%)$ had synchronous metastases. The other $44 \%$ had confirmed histopathological analysis of RCC metastasis by percutaneous biopsy. At the time of spinal surgery, $8 \%$ of the patients had solitary metastases only in the spine; $42 \%$ of patients had bone metastases at other sites. Additional sites of metastasis included the lungs $(33 \%)$, liver $(7 \%)$, lymph nodes $(5 \%)$, kidneys $(3 \%)$, and brain $(2 \%)$. None of the patients received radiation therapy of symptomatic level before surgery.

Metastasectomy and instrumental reconstruction were performed for 39 patients, whereas 61 patients obtained decompression with instrumental stabilization. Three patients underwent metastasectomy before nephrectomy due to kyphotic deformity of the thoracic spine. Restoration of the anterior spinal column via vertebral replacement provided correction of deformity. There were only 23 patients who received radiotherapy after surgery (5 with metastasectomy and 18 with decompression).

Preoperative neurological grades according to Frankel and its modifications after surgery are reported in Figure 1. Improvement in neurological function was observed overall in the study population. The 50 nonambulatory patients showed improvement in ability to walk after surgery. There was significant difference between Frankel A, B, and $\mathrm{C}$ and Frankel $\mathrm{D}$ and $\mathrm{E}$ at baseline and after surgery
$(P<.0001)$. Overall, $79 \%$ of patients were able to walk after surgery.

All patients had spinal pain before surgery. The baseline mean VAS score was 7.1 (95\% confidence interval $[\mathrm{CI}]=6.7-7.4)$. In the postoperative period, collected on the seventh day after surgery, it was 2.6 $(95 \% \mathrm{CI}=2.3-2.8)$. According to a paired Wilcoxon test, a significant decrease in referred pain after surgery was observed $(P<.0001)$. None of the patients reported worsening of pain.

At the last follow up, 89 of the 100 patients had died, and 11 patients were still alive. The median overall survival time of all patients was $22(95 \%$ CI $=17-29$ ) months, with 3- and 5-year survival rates after spine surgery of $29.7 \%$ and $12 \%$, respectively. For analysis, patients were divided into groups based on type of surgery (Table 2). Surprisingly, there were no statistically significant differences in survival time between patients who obtained metastasectomy versus the decompression procedure $(P$ $=.750$; Figure 2 ). Next, we stratified patients by exposure to adjuvant therapy (Table 3). The difference between the median survival of the targeted therapy versus cytokine therapy was statistically significant according to a log-rank test $(P=.012$; Figure 3$)$.

Sixteen patients experienced symptomatic local recurrence in the operated spine. Local progression of the disease was observed mainly in the first year after surgery (median time $=5$ months). There were 3 cases after metastasectomy and 13 cases after decompression $\left(\chi^{2}=2.35, P=.125\right)$. However, in local progression-free survival analysis, we observed a significant difference in the first year after surgery (Figure 4). Only 1 patient with targeted therapy experienced local progression of the disease (Figure 5).

There were in total 51 complications in 38 patients (Table 4). Eight patients had neurological deficit: 7 cases of temporary and 1 case of irreversible (after preoperative embolization). Wound complications (surgical site infection, wound hematoma, or liquorrhea) were observed in 17 cases. Implant-related complications (implant failure or junctional disorders) developed in 14 patients. Twelve patients had major medical morbidity (cardiac events, ileus, pneumonia, thrombosis, or urinary tract infection).

\section{DISCUSSION}

Metastases originating from RCC are difficult to manage. They tend to be osteolytic, hypervascular, 
Table 2. Characteristics of patients by surgery.

\begin{tabular}{|c|c|c|c|}
\hline Parameters & Metastasectomy $(n=39)$ & Decompression $(n=61)$ & $P$ Value \\
\hline Sex, $n$ & & & .372 \\
\hline Male & 32 & 44 & \\
\hline Female & 7 & 17 & \\
\hline Age, mean $(95 \% \mathrm{CI}), \mathrm{y}$ & $60.6(57.6-63.7)$ & $57.7(54.6-60.9)$ & .186 \\
\hline No. of levels & & & $.004 *$ \\
\hline 1 & 35 & 40 & \\
\hline 2 & 2 & 20 & \\
\hline 3 & 2 & 1 & \\
\hline Neurological status before surgery, $\mathrm{n}$ & & & $<.0001^{*}$ \\
\hline Frankel A, B, C & 2 & 48 & \\
\hline Frankel D, E & 37 & 13 & \\
\hline Revised Tokuhashi score, mean $(95 \%$ CI $)$ & $12.3(11.8-12.9)$ & $10.4(9.6-11.0)$ & $.0001 *$ \\
\hline \multirow{2}{*}{\multicolumn{4}{|c|}{ Metastases, $\mathrm{n}$}} \\
\hline & & & \\
\hline Synchronous & 28 & 38 & 446 \\
\hline Solitary spinal metastases & 4 & 4 & .774 \\
\hline Extravertebral bone metastases & 7 & 35 & $<.001 *$ \\
\hline Additional visceral metastases & 13 & 36 & $.021 *$ \\
\hline Radical nephrectomy prior spine surgery, $\mathrm{n}$ & 36 & 51 & .339 \\
\hline Targeted therapy after spine surgery, $\mathrm{n}$ & 7 & 19 & .217 \\
\hline
\end{tabular}

Abbreviation: CI, confidence interval; SINS, Spinal Instability Neoplastic Score.

*Statistically significant difference.

and more resistant to systemic and radiation therapy than other metastases. ${ }^{7,8}$ Spinal RCC metastases may cause pathologic fractures and spinal cord compression that severely compromise performance status and quality of life, although there has been considerable progress in the treatment of advanced or metastatic RCC using targeted agents. ${ }^{6,9}$ The presence of bone metastases is

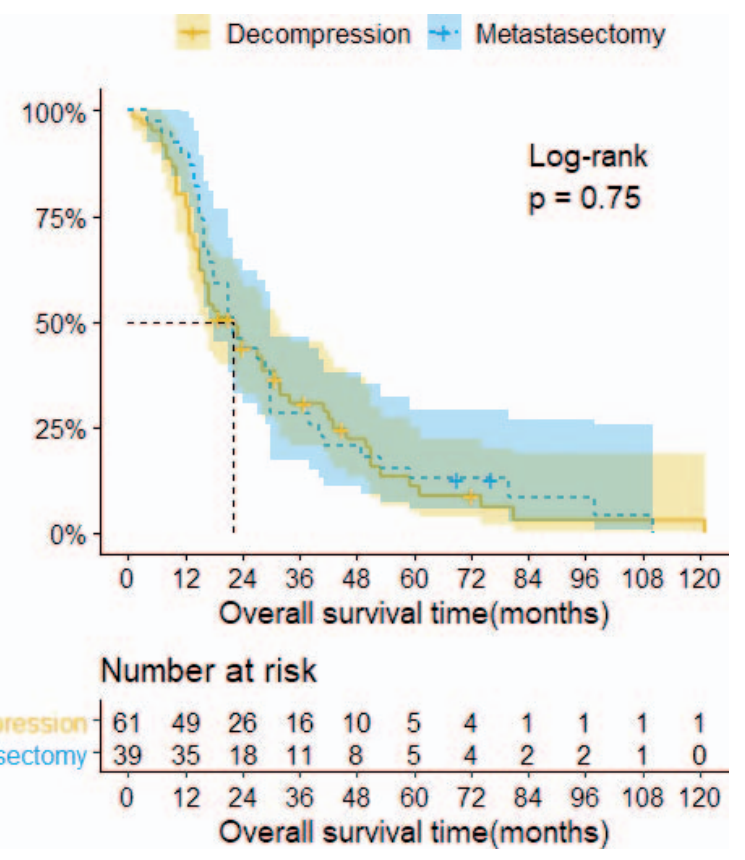

Figure 2. Kaplan-Meier survival curves with confidence intervals (Cls) stratified by surgery. The median overall survival of patients with decompression was 22 months $(95 \% \mathrm{Cl}=16-32)$, 3- and 5-year survival rates $30.7 \%$ and $11.2 \%$, respectively. The median overall survival of patients with metastasectomy was 22 months $(95 \% \mathrm{Cl}=18-30)$, 3- and 5-year survival rates $28.2 \%$ and $12.8 \%$, respectively. associated with a clinically significant negative impact on survival. ${ }^{10}$

Surgery of spinal lesions in the setting of metastatic disease is fundamentally not designed to alter the survival of the patient. Similar to our findings, mechanical decompression of neural structures by laminectomy and spinal stabilization with instrumentation reduce pain and restore neurological function. ${ }^{11,12}$ Several reports were published regarding the effect of surgical treatment on survival rate among patients with RCC metastases. Decompression surgery provides a range of median survival of 11.4-14.1 months. ${ }^{2,13,14}$

Surgery remains an integral component of the therapeutic armamentarium for advanced and metastatic RCC. Several publications showed that treatment options for patients with spine tumors have undergone a substantial paradigm shift from goals that were only palliative to curative strategies including complete en bloc resection of the tumor. ${ }^{15-17}$ Metastasectomy also plays a role for carefully selected patients. According to Petteys et al, ${ }^{14}$ metastasectomy provides long-term diseasefree survival, especially those with solitary metastases of RCC, which is important as disease-free survival may be used as a surrogate endpoint for overall survival. ${ }^{18}$ Kato et $\mathrm{al}^{19}$ showed, in reporting their results of patients treated with complete resection for solitary metastases of $\mathrm{RCC}$, that median overall survival after metastasectomy was 130 months. 
Table 3. Characteristics of patients by adjuvant therapy.

\begin{tabular}{|c|c|c|c|}
\hline Parameters & Targeted Therapy $(\mathrm{n}=26)$ & Cytokine Therapy $(n=74)$ & $P$ Value \\
\hline Sex, $\mathrm{n}$ & & & 1.000 \\
\hline Male & 20 & 56 & \\
\hline Female & 6 & 18 & \\
\hline Age, mean $(95 \% \mathrm{CI}), \mathrm{y}$ & $57.1(52.5-61.8)$ & $59.8(56.7-62.9)$ & \\
\hline No. of levels & & & $.015^{*}$ \\
\hline 1 & 15 & 57 & \\
\hline 2 & 11 & 11 & \\
\hline 3 & 0 & 3 & \\
\hline Neurological status before surgery, $\mathrm{n}$ & & & $<.0001^{*}$ \\
\hline Frankel A, B, C & 3 & 47 & \\
\hline Frankel D, E & 23 & 27 & \\
\hline Revised Tokuhashi score, mean $(95 \%$ CI $)$ & $11.1(10.2-12.0)$ & $11.6(11.1-12.1)$ & .328 \\
\hline SINS, mean $(95 \% \mathrm{CI})$ & $11.3(9.6-13.1)$ & $10.9(9.9-11.9)$ & .458 \\
\hline \multicolumn{4}{|l|}{ Metastases, $\mathrm{n}$} \\
\hline Synchronous & 11 & 55 & $.007 *$ \\
\hline Solitary spinal metastases & 2 & 6 & 1.000 \\
\hline Extravertebral bone metastases, $\mathrm{n}$ & 13 & 29 & .364 \\
\hline Additional visceral metastases & 13 & 37 & 1.000 \\
\hline Radical nephrectomy prior spine surgery, $\mathrm{n}$ & 24 & 63 & .505 \\
\hline Metastasectomy, n & 7 & 32 & .167 \\
\hline
\end{tabular}

Abbreviation: CI, confidence interval; SINS, Spinal Instability Neoplastic Score.

*Statistically significant difference.

However, according to our results, the overall survival time of patients with metastasectomy insignificantly differs from patients with decompression procedure. Nevertheless, metastasectomy showed good results in terms of local control. Local

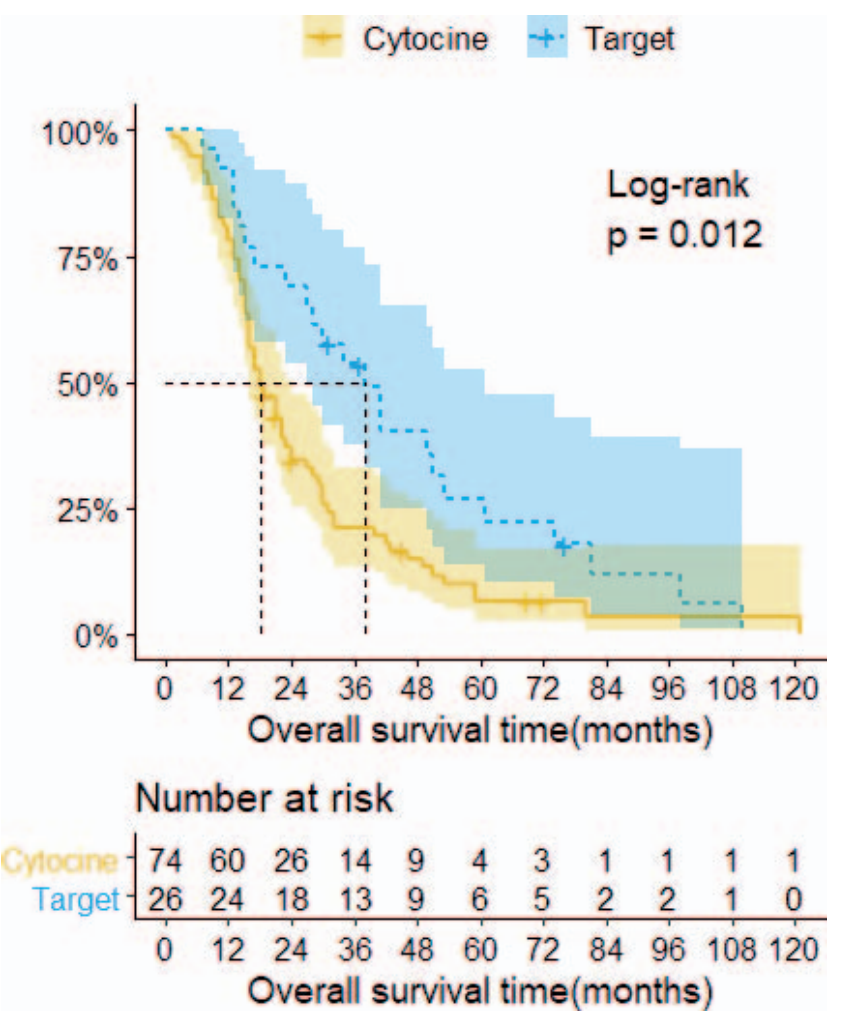

Figure 3. Kaplan-Meier survival curves with confidence intervals (Cls) stratified by adjuvant therapy. The median overall survival of patients with cytokine therapy was 18 months $(95 \% \mathrm{Cl}=16-24)$, 3- and 5-year survival rates $21 \%$ and $6.6 \%$, respectively. The median overall survival of patients with targeted therapy was 38 months $(95 \% \mathrm{Cl}=27-61)$, 3- and 5-year survival rates $53.6 \%$ and $26.8 \%$, respectively. progression of disease was observed in the first year after surgery more often in patients who had partial tumor removal for spinal cord decompression. This is important because only a minority of our patients received radiotherapy after surgery. Also, we concluded that patients who received adjuvant targeted therapy lived longer regardless of the operation type. The results of our study regarding consistency do not oppose the trend suggested in the literature by researchers, ${ }^{19-21}$ where the majority of

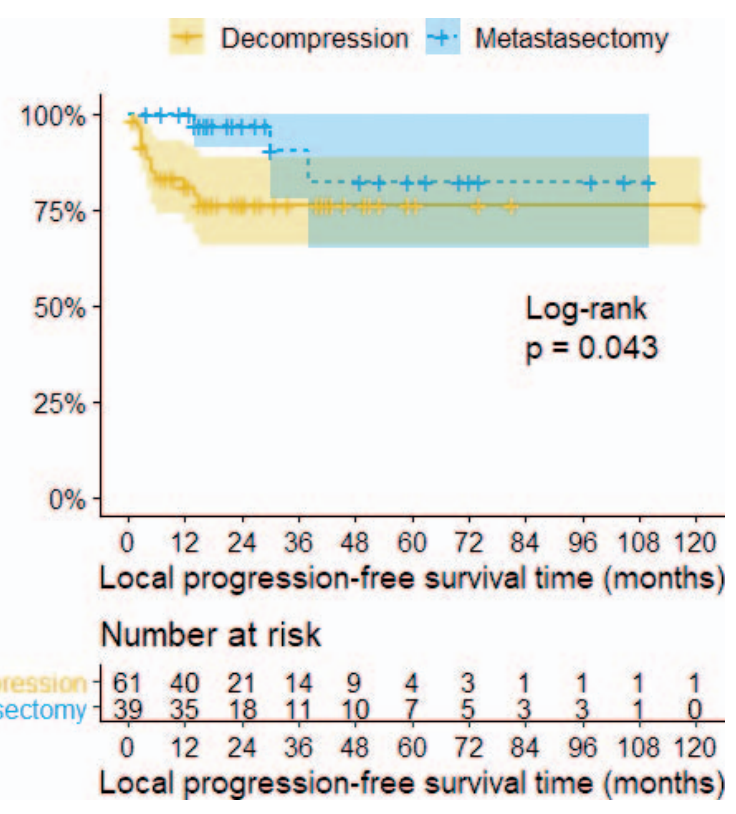

Figure 4. Kaplan-Meier survival curves with confidence intervals (Cls) stratified by surgery. The 3- and 5-year local progression-free survival rare in patients with decompression was $76.4 \%$. The 3 - and 5 -year local progressionfree survival rates in patients with metastasectomy were $90.6 \%$ and $82.4 \%$, respectively. 


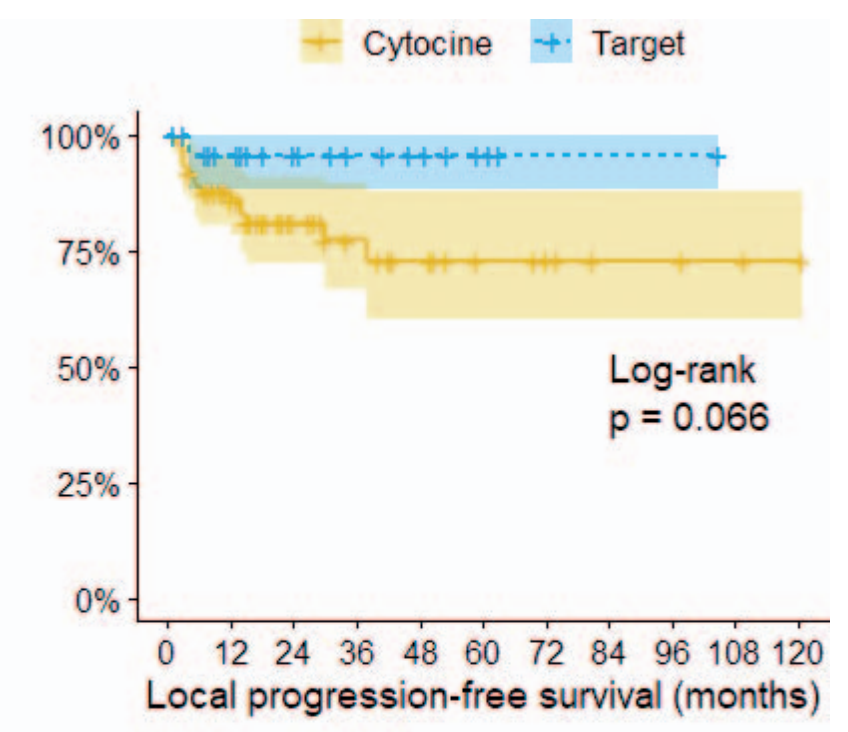

\section{Number at risk}

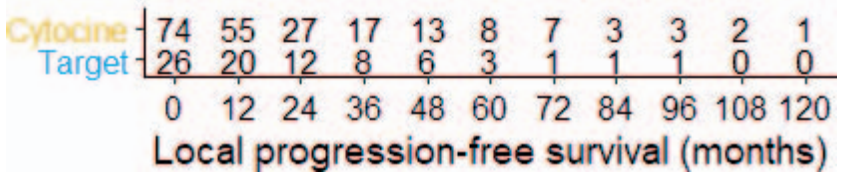

Figure 5. Kaplan-Meier survival curves with confidence intervals (Cls) stratified by adjuvant therapy. The 3- and 5-year local progression-free survival rates in patients with cytokine therapy were $77.4 \%$ and $72.9 \%$, respectively. The 3- and 5-year local progression-free survival rate in patients with targeted therapy was $95.8 \%$.

patients obtained targeted therapy after surgery. We confirm the importance of multimodal management of spinal metastases arising from RCC.

Our study had several limitations. Over the 11year period, recruitment protocols for the treatment of RCC have changed. It was impossible to estimate the effect of various combinations of systemic therapy on survival. We also did not provide a comparison between the patients who received the targeted therapy and metastasectomy due to the small number of patients.

\section{CONCLUSIONS}

The current results did not show that complete excision of spinal RCC metastases is associated with long-term overall survival. Metastasectomy is effec-

Table 4. Complications.

\begin{tabular}{lccc}
\hline Parameters & $\begin{array}{c}\text { Metastasectomy } \\
(\mathbf{n}=\mathbf{3 9})\end{array}$ & $\begin{array}{c}\text { Decompression } \\
(\mathbf{n}=\mathbf{6 1})\end{array}$ & $\begin{array}{c}\boldsymbol{P} \\
\text { Value }\end{array}$ \\
\hline General complications & 5 & 7 & .880 \\
Neurologic deficit & 2 & 6 & .367 \\
Wound hematoma & 2 & 2 & .827 \\
Surgical site infection & 4 & 7 & .873 \\
Liquorrhea & 0 & 2 & .334 \\
Adjacent segment disease & 6 & 3 & .117 \\
Implant failure & 3 & 2 & .264 \\
\hline
\end{tabular}

tive for local control of tumors. A part of the multimodal treatment of this disease is the targeted therapy, which should be used after metastasectomy to improve outcomes.

\section{REFERENCES}

1. Macedo F, Ladeira K, Pinho F, et al. Bone metastases: an overview. Oncol Rev. 2017;11(1):321. doi:10.4081/oncol.2017. 321

2. Jackson RJ, Loh SC, Gokaslan ZL. Metastatic renal cell carcinoma of the spine: surgical treatment and results. $J$ Neurosurg. 2001;94(1 Suppl):18-24. http://www.ncbi.nlm.nih. gov/pubmed/11147860.

3. Woodward E, Jagdev S, McParland L, et al. Skeletal complications and survival in renal cancer patients with bone metastases. Bone. 2011;48(1):160-166. doi:10.1016/j.bone.2010. 09.008

4. Jung ST, Ghert MA, Harrelson JM, Scully SP. Treatment of osseous metastases in patients with renal cell carcinoma. Clin Orthop Relat Res. 2003;409(409):223-231. doi:10.1097/01.blo. $0000059580.08469 .3 \mathrm{e}$

5. Sundaresan N, Boriani S, Okuno S. State of the art management in spine oncology: a worldwide perspective on its evolution, current state, and future. Spine (Phila Pa 1976). 2009;34(22 Suppl):S7-S20. doi:10.1097/BRS.0b013e3181bac476

6. Motzer RJ, Escudier B, McDermott DF, et al. Nivolumab versus everolimus in advanced renal-cell carcinoma. $N$ Engl $J$ Med. 2015;373(19):1803-1813. doi:10.1056/NEJMoa1510665

7. Coleman RE. Clinical features of metastatic bone disease and risk of skeletal morbidity. Clin Cancer Res. 2006;12(20 Pt 2):6243s-6249s. doi:10.1158/1078-0432.CCR-06-0931

8. Ljungberg $\mathrm{B}$, Bensalah $\mathrm{K}$, Canfield $\mathrm{S}$, et al. EAU guidelines on renal cell carcinoma: 2014 update. Eur Urol. 2015;67(5):913-924. doi:10.1016/j.eururo.2015.01.005

9. Motzer RJ, Hutson TE, Tomczak P, et al. Overall survival and updated results for sunitinib compared with interferon alfa in patients with metastatic renal cell carcinoma. J Clin Oncol. 2009;27(22):3584-3590. doi:10.1200/JCO.2008.20.1293

10. McKay RR, Kroeger N, Xie W, et al. Impact of bone and liver metastases on patients with renal cell carcinoma treated with targeted therapy. Eur Urol. 2014;65(3):577-584. doi:10.1016/j.eururo.2013.08.012

11. Sciubba DM, Gokaslan ZL. Diagnosis and management of metastatic spine disease. Surg Oncol. 2006;15(3):141-151. doi:10.1016/j.suronc.2006.11.002

12. Park JH, Jeon SR. Pre- and postoperative lower extremity motor power and ambulatory status of patients with spinal cord compression due to a metastatic spinal tumor. Spine (Phila Pa 1976). 2013;38(13):E798-802. doi:10.1097/BRS. 0b013e3182927559

13. Quraishi NA, Purushothamdas S, Manoharan SR, Arealis G, Lenthall R, Grevitt MP. Outcome of embolised vascular metastatic renal cell tumours causing spinal cord compression. Eur Spine J. 2013;22(Suppl 1):27-32. doi:10.1007/ s00586-012-2648-6

14. Petteys RJ, Spitz SM, Rory Goodwin C, et al. Factors associated with improved survival following surgery for renal cell carcinoma spinal metastases. Neurosurg Focus. 2016;41(2):E13. doi:10.3171/2016.5.FOCUS16145 
15. Tomita K, Kawahara N, Kobayashi T, Yoshida A, Murakami H, Akamaru T. Surgical strategy for spinal metastases. Spine (Phila Pa 1976). 2001;26(3):298-306. doi:10.1097/00007632-200102010-00016

16. Sakaura H, Hosono N, Mukai Y, Ishii T, Yonenobu K, Yoshikawa H. Outcome of total en bloc spondylectomy for solitary metastasis of the thoracolumbar spine. J Spinal Disord Tech. 2004;17(4):297-300. doi:10.1097/01.bsd.0000096269. $75373.9 \mathrm{~b}$

17. Sundaresan N, Boriani S, Okuno S. State of the art management in spine oncology: a worldwide perspective on its evolution, current state, and future. Spine (Phila Pa 1976). 2009;34(22 Suppl):S7-20. doi:10.1097/BRS.0b013e3181bac476

18. Halabi S, Rini B, Escudier B, Stadler WM, Small EJ. Progression-free survival as a surrogate endpoint of overall survival in patients with metastatic renal cell carcinoma. Cancer. 2014;120(1):52-60. doi:10.1002/cncr.28221

19. Kato S, Murakami H, Demura S, et al. Spinal metastasectomy of renal cell carcinoma: a 16-year single center experience with a minimum 3-year follow-up. J Surg Oncol. 2016;113(5):587-592. doi:10.1002/jso.24186

20. Alt AL, Boorjian SA, Lohse CM, Costello BA, Leibovich BC, Blute ML. Survival after complete surgical resection of multiple metastases from renal cell carcinoma. Cancer. 2011;117(13):2873-2882. doi:10.1002/cncr.25836
21. Josephides E, Rodriguez-Vida A, Galazi M, Chowdhury $\mathrm{S}$, Suder A. The role of metastasectomy in renal cell carcinoma. Expert Rev Anticancer Ther. 2013;13(12):1363-1371. doi:10. $1586 / 14737140.2013 .856762$

Disclosures and COl: On behalf of all authors, the corresponding author states that there is no conflict of interest. There is no funding source.

Corresponding Author: Nikita Zaborovskii, MD, PhD, Spine Surgery and Oncology Service, R.R. Vreden Russian Research Institute of Traumatology and Orthopedics, Saint-Petersburg, st. A. Baykova, 8, Russia, 195427. Phone: +7 81267095 52; Email: n.zaborovskii@yandex.ru.

Published 22 January 2021

This manuscript is generously published free of charge by ISASS, the International Society for the Advancement of Spine Surgery. Copyright (C) 2020 ISASS. To see more or order reprints or permissions, see http://ijssurgery.com. 